For convenience of operation, all the controls and gauges have been collected together into one mobile unit. Oil at high pressure is supplied through flexible tubes to the control unit, where it is metered and reduced in pressure and distributed through a further set of flexible tubes to the six jacks inserted between the test frame and the specimen. Although the hydraulic jacks will be used in most experimental work, loads can also be applied by means of dead weights or by air bags acting between the specimen and the reaction framework. For strain measurement on test specimens, it is intended to use electrical resistance methods, acoustic gauges and mechanical dial-gauge strain indicators.

The first work to be undertaken in the new Laboratory will consist of experiments on inter-connected concrete beams prestressed longitudinally and transversely, the aim of which is to compare the performance of the structure in the elastic range with the predictions of theory, and to observe the form of the redistribution of load among the beams after oracking.

The main lines of work of the other sections of the Research Station have already been mentioned; space does not allow these to be fully described, but the following items are of general interest. The Physics and Chemistry Section is working on a semi-micro colorimetric method, using a 'Spekker' absorptiometer, for analysing silicates and other related compounds found in the materials from which concrete is made; this allows the time required for the analysis of cement, for example, to be reduced to one-third or one-quarter of that required when ordinary methods are used.

The section is also engaged on a study of efflorescence on concrete. This phenomenon arises from the leaching out to the surface of lime liberated during the hardening of cement, and little is known of the factors that influence its appearance in any particular circumstances. The work has shown that the physical structure of the concrete and the texture of the surface have considerable effect, and concrete of a wide range of compositions and surface textures is being prepared to determine the conditions in which efflorescence does or does not appear. Apparatus has also been designed for locating and measuring the position of reinforcement in hardened concrete and for measuring the elasticity of concrete by determining the velocity of sound. A study is also being made of surface-active agents used for improving the workability and durability of concrete, while in the future it is hoped to make a fundamental study of the micro-structure of hardened concrete.

In the Concrete and Concrete Materials Section research is being carried out on the quantitative measurement of the shape and surface texture of aggregates by determining the resistance to the flow of a fluid through a bed of the particles, and an attempt is being made to relate the shape and texture with the workability of concrete made, from similar aggregates. In the work devoted to aggregates a study is also being made of their absorption characteristics, of the methods of determining their moisture content and of the principles governing the control of moisture content of aggregates on works sites. The Section has completed the collection of data on the mix proportions required to produce conerete of predetermined characteristics with aggregates of $\frac{3}{8}$-in. maximum size, and an examination is now in progress of the factors affecting the design of mixes of very high strength.
The work on steam-curing done by the Engineering Section has made it possible to correlate and reconcile the apparently conflicting results hitherto obtained elsewhere and to gain some insight into the underlying principles involved. A considerable amount of development work is being done on the surface treatment of concrete. This has been concentrated mainly on the use of precast concrete slabs to be used as cladding for buildings or for permanent shuttering, but some work on the surface treatment of in situ concrete and external renderings has been done. Emphasis is given to the production of surfaces characteristic of concrete by exposing the aggregate in a number of different ways, and a wide range of coloured and textured finishes has been produced. Tests are being made on the weathering qualities of these slabs both in rural and industrial areas. Investigations are also being made on the production of similar textured surfaces for roads and paved areas, and on the development of prestressing for concrete roads in order to overcome the need for joints and to allow comparatively long lengths of slabs to be laid continuously. It is hoped in this way to save cost and improve the appearance and riding quality. The first experiments on prestressing concrete roads in Great Britain were made at Wexham Springs in 1950 with a simple method of prestressing developed by the staff of the Association.

In co-operation with the Research Committee of the Cast Stone and Cast Concrete Products Industry, work has just begun on a study of problems involved in the compaction of concrete by vibration, in general, and the use of vibration in making precast concrete products, in particular. The work is still in its early stages, but it is planned to test a whole range of commercial vibrating equipment which will also be used to form a permanent exhibition at Wexham Springs.

In 1950 the Association set up a training centre close to the Research Station, and five-day residential courses are held on such subjects as prestressed concrete, design of concrete mixes, quality control of concrete, farm buildings, roads and new developments in technique. Lectures and demonstrations are given, in the main, by members of the research staff; but in some instances outside specialists lecture on their own particular subjects. During the past seventeen months more than five hundred students have attended these courses.

\section{CENTRAL BUILDING RESEARCH INSTITUTE, INDIA}

$T$

HE foundation stone of the last of the series of eleven national laboratories being set up by the Council of Scientific and Industrial Research of India was laid at Roorkee by the Hon. Mr. Sri Prakasa, Minister for Natural Resources and Scientific Research, on February 10. Roorkee has long been well known as an engineering centre. The Thomason Civil Engineering College at Roorkee was a pioneer institution in India, and last year it became the University of Roorkee; now it is accommodating the new Research Institute until such time as the Institute's own building is ready.

Building research was originally conceived as one of the nine divisions of the National Physical Laboratory recently set up at Delhi; but the prevailing 
acute housing shortage has heavily underlined the importance of building research, and quite justifiably it has been decided that building research should have a national laboratory to itself, in accordance with the recommendations made by a Building Research Committee at the end of 1943. A Building Research Unit set up in May 1947 is at present working with a skeleton staff in two hangars loaned for the purpose by the University. The Unit has been carrying on useful investigations into soil stabilization and has already obtained important results on the treatment of lime sludges from sugar factories, on cheap houses and on various problems connected with brick-making. It has also published a few brochures on low-cost housing and village housing.

For an institute devoted to building research, Roorkee was the obvious choice. A suitable 10-acre site on its eastern border has been leased by the University of Roorkee to the Council of Scientific and Industrial Research for housing the Institute. The Council has also purchased from the Defence Ministry an S.W.P. hangar (floor space about 3,500 sq. yards), and this is eventually to house the Institute's engineering division and its workshop.

The Board of Scientific and Industrial Research has made provision for a capital expenditure of Rs. 16 lakhs for the Institute, to be spread over a period of three years, and for an annual recurring expenditure of Rs. 4.25 lakhs.

The Institute will undertake research on building materials, on engineering and structural aspects of buildings and their foundations; on problems of comfort in buildings and their durability and the speed of construction. Its activities will naturally include basic research and fundamental studies, such as X-ray investigations and differential thermal analysis of clays and their electro-chemical and rheological properties, strains and stresses in structures and comfort in buildings. It will afford facilities for training men for diverse types of construction and help in the creation of a body of trained men in India.

The functions of the Institute include : (1) examination of building materials in common use and the methods of applying them with the view of economy and improvements ; (2) examination of new materials and processes evolved at the Institute and elsewhere ; (3) scientific diagnosis of the causes of failures in materials themselves or in their application; (4) dissemination of useful information and fostering the growth of a scientific spirit and outlook in the building industry in India; (5) preparation of standards of materials and codes of practices for various aspects of building construction.

From a slightly different point of view, the subjects of research may be grouped into three main categories: (i) efficiency of buildings, which includes problems like heating, lighting and ventilation; (ii) properties of materials used in buildings, such as cement, plaster, bricks; and (iii) structure and strength of materials.

Dr. J. N. Mukherjee, a distinguished soil chemist, hitherto working with the Indian Council of Agricultural Research, has been appointed director of the new Institute.

Pandit Jawaharlal Nehru, addressing a large gathering on the occasion of the laying of the foundation stone, said that housing is one of the most pressing problems of India. Millions of houses are needed and it would be futile to expect the
Government to construct them. "The resources of the Government may be limited, but the resources of the people should never be limited." He disapproved of the attitude of those who looked towards the Government for "parental" help in everything; "the British Government might have acted in this way, but with the achievement of independence people must learn to be self-reliant". Pandit Nehru stressed that manual work must not be looked down upon. He expressed the desire that by the time he visited Roorkee next the students would have constructed some building with their own hands. $\mathrm{He}_{\theta}$ added he had seen such things done in the United States and had been impressed by them.

Sir Shanti Swarup Bhatnagar, director of Scientific and Industrial Research, Government of India, said that the eleven national laboratories are only the first stage, and that some further laboratories were already under active consideration. In particular, funds have been provided by industry for a silk and rayon research centre. A national laboratory for electronics and another for atomic energy are also needed.

Laying the foundation stone, the Hon. Mr. Sri Prakasa remarked that in India great attention has been paid in the past to houses for gods, and it is time now to attend to comfortable housing of the common man. Mr. Hart, vice-chancellor of the University of Roorkee, and Dr. Mukherjee, director of the Institute, also gave addresses.

\section{INTERNAL FRICTION OF SOLIDS}

THE Physical Society (Acoustics Section), the

Institute of Metals and the British Iron and Steel Institute held a combined meeting on March 15 at 4 Grosvenor Gardens, London, W.1, at which ten speakers discussed theoretical and practical aspects of the internal friction of solids.

Prof. A. H. Cottrell (University of Birmingham) opened the proceedings with a survey of generally accepted views on the main causes of internal friction or loss of energy during the vibration of solids. For the sake of brevity he did not discuss friction associated with the magnetostrictive properties of ferromagnetic metals, and for the four main causes he outlined: friction due to the ordering of solute atoms; friction inside single crystals arising from the movements of regions of disarray, that is, of dislocations; thermo-elastic friction due to thermal currents between adjoining crystals; and friction accompanying slip along grain boundaries. The first two oceur in both single crystals and in polyerystalline solids, but the other two are restricted to the latter.

The idea of damping due to the ordering of solute atoms was first conceived by Snoek $^{1}$, a typical case occurring when the carbon (or nitrogen) atoms which are dissolved interstitially in $\alpha$-iron, that is, a crystal normally of the body-centred cubic type, diffuse under vibratory stress to positions between pairs of $\alpha$-iron atoms in the line of stress from positions between orthogonal pairs. For carbon in iron this diffusion process has a time constant $\tau$ of about a second at room temperature. This type of contribution to friction has for its main characteristics : a maximum damping for vibrations of angular frequency $\omega$, where $\omega=1 / \tau$, and a variation with frequency according to the usual relaxation law, that is, it varies as $\omega \tau /\left(1+\omega^{2} \tau^{2}\right)$; independence of 